\title{
LA REPRODUCCIÓN ASISTIDA EN EUROPA: LA LABOR ARMONIZADORA DEL TRIBUNAL EUROPEO DE DERECHOS HUMANOS*
}

\author{
ASSISTED REPRODUCTION IN EUROPE: \\ HARMONIZING WORK OF THE EUROPEAN COURT OF HuMAN RightS
}

\author{
Ma del Pilar Molero Martín-Salas ${ }^{* *}$ \\ Universidad de Castilla-La Mancha. España \\ Mariapilar.molero@uclm.es
}

RESUMEN: Uno de los principales avances cientificos de las últimas décadas ha sido la reproducción asistida. Ello ha provocado la aparición de nuevos problemas jurídicos que han sido resueltos en Europa por sus Estados miembro de manera heterogénea, convirtiendo la interpretación del Tribunal Europeo de Derechos Humanos en estos uiltimos años en necesaria y crucial para entender la regulación europea al respecto. En este trabajo se muestra la labor de interpretación realizada por el Tribunal respecto a la materia, y su importante labor de armonización ante la diversidad de regulación de los Estados miembro.

ABSTRACT: One of the main scientific advances of recent decades has been assisted reproduction. This has led to the emergence of new legal problems that have been solved in Europe for its member states, heterogeneously, making the interpretation of the European Court of Human Rights in recent years in something necessary and crucial for understanding the european regulation in this regard. This work shows, the work of interpretation by the Court on the matter, and the important work of harmonization with the diversity of regulation of the member states.

PALABRAS CLAVE: Reproducción asistida, Europa, Tribunal Europeo de Derechos Humanos.

KEYWORDS: Sssisted reproduction, Europe, European Court of Human Rights.

\section{INTRODUCCIÓN}

Los imparables avances de la ciencia suponen un constante desafío para el Derecho. Los Estados no pueden mantenerse impasibles ante esta evolución y la aparición de nuevas necesidades, ante las cuales la sociedad reclama, en muchos casos, que éstas sean atendidas.

\footnotetext{
* Trabajo recibido el 16 de noviembre de 2015 y aprobado el 17 de agosto de 2016.
}

** Doctora en Derecho. Profesora de Derecho Constitucional. Universidad de Castilla-La Mancha. España. Investigadora en la Universidad de Pisa. Italia. Licenciada y DEA en Derecho. 
El problema es que los avances científicos en la mayoría de los casos afectan directamente a lo más esencial de la naturaleza humana, y suponen una constante revisión de la concepción que se tiene con respecto a derechos tan básicos como la vida, la dignidad o la integridad de la persona.

Uno de los aspectos que más ha evolucionado en Europa en las últimas décadas, y que más interés ha suscitado en la sociedad -por la esperanza y las oportunidades que ofrece a innumerables personas que desean tener un hijo, y no pueden hacerlo de manera natural- es la reproducción asistida.

Desde el momento en que se inicia el análisis de un tema como éste, es fácil observar que son numerosos los elementos jurídicos interesantes, por las diversas aportaciones al respecto, y porque suelen suscitar con facilidad la polémica y la discrepancia. Por ello, más allá de la regulación concreta que se ha llevado cabo por los diversos Estados, es interesante analizar la interpretación dada por el Tribunal Europeo de Derechos Humanos (en adelante TEDH) en estos últimos años.

Como tendremos oportunidad de ver a lo largo de las siguientes páginas, dicha interpretación resulta crucial. Sin duda se trata de un tema espinoso para el que no existe una regulación unánime entre los Estados miembro. El Convenio para la protección de los derechos humanos y de las libertades fundamentales (en adelante Convenio) ${ }^{1}$ tampoco sirve de gran ayuda, pues en ninguno de sus preceptos se regula de manera expresa la reproducción o la existencia de un derecho respecto a la misma. Por todo ello ha tenido que ser el Tribunal, a través de sus pronunciamientos, el que armonice e interprete respecto a esta materia.

Es indiscutible que la ciencia y la medicina pueden hacerlo, y que este tipo de técnicas son una realidad, pero el avance científico debe ir acompañado de una correcta regulación al respecto. "La ciencia y la tecnología están preparadas para ello pero, para su efectividad, precisan del acompañamiento de recursos económicos, políticos y legislativos" 2 .

\section{EL DERECHO A LA REPRODUCCIÓN}

en el Convenio de Roma y su encaje en el artículo 8

Si analizamos el texto literal del Convenio no se reconoce de manera explícita el derecho a la reproducción, y aún menos la reproducción asistida. Sin embargo,

1 Hecho en Roma el 4 de noviembre de 1950.

2 SÁNCHEZ (2013), p. 827. 
sí encontramos diversas sentencias pronunciadas por el TEDH en estos últimos años, relacionadas de manera directa con el tema que nos ocupa.

Sin duda dicha interpretación se ha realizado en base al artículo 8 del Convenio, que regula el derecho al respeto a la vida privada y familiar ${ }^{3}$, y que con el paso de los años ha ido flexibilizando sus márgenes y ampliando su contenido.

Aunque el precepto dice textualmente "respeto a la vida privada y familiar", lo cierto es que la interpretación amplia realizada por el TEDH ha permitido considerar que también da cobertura a otras realidades de manera implícita tales como el derecho a la reproducción.

Analizando diversas sentencias del Tribunal, podemos observar su consideración respecto a ciertos temas que provocan una mayor sensibilidad ética y social. Precisamente, la amplitud y la flexibilidad a la que me refiero se ha producido especialmente en este tipo de casos. Algunos autores se han referido a este aspecto, así Penasa habla del "onore procedurale", que se derivaría de la jurisprudencia del TEDH cuando debe enfrentarse a cuestiones éticas, sociales o científicas especialmente sensibles ${ }^{4}$.

Un claro ejemplo de ello se produce en el caso Pretty 5 , en el que se expone claramente que la "noción de autonomía personal refleja un principio importante que subtiende la interpretación de las garantías del artículo 8”. Asimismo recuerda que la noción de vida privada "es una noción amplia, sin una definición exhaustiva”. Alude el Tribunal a otros aspectos que también forman parte del artículo

3 Artículo 8 Derecho al respeto a la vida privada y familiar

1. Toda persona tiene derecho al respeto de su vida privada y familiar, de su domicilio y de su correspondencia.

2. No podrá haber injerencia de la autoridad pública en el ejercicio de este derecho, sino en tanto en cuanto esta injerencia esté prevista por la ley y constituya una medida que, en una sociedad democrática, sea necesaria para la seguridad nacional, la seguridad pública, el bienestar económico del país, la defensa del orden y la prevención del delito, la protección de la salud o de la moral, o la protección de los derechos y las libertades de los demás.

4 Penasa (2013).

5 Pretty contra Reino Unido (2002): Sentencia Tribunal Europeo de Derechos Humanos Estrasburgo (Sección 4), de 29 de abril de 2002 (TEDH 2002\23). La demandante, la señora Pretty, padece esclerosis lateral amiotrófica ("ELA"), una enfermedad degenerativa que en su caso se encuentra en un estado muy avanzado. Le ocasiona graves sufrimientos físicos y psicológicos, y puesto que no tiene posibilidad de quitarse la vida por ella misma, solicita a los tribunales interiores que permitan que su marido la ayude a morir, cuestión que está castigada penalmente en Reino Unido. Tras la negativa por parte de los tribunales, acude al TEDH esperando que la respuesta sea diferente. 
8 como son la integridad física y moral, la identificación sexual, el nombre, la orientación sexual y la vida sexual ${ }^{6}$.

Centrándonos en el tema que nos ocupa, sin duda una de las sentencias más importantes es la dictada para el caso Evans contra Reino Unido 7 . Vuelve a reiterar el Tribunal que la noción de vida privada es amplia y que también puede englobar aspectos de su identidad física y social, "concretamente el derecho a la autodeterminación, el derecho al desarrollo personal y el derecho a establecer y mantener relaciones con otros seres humanos y el mundo exterior cubriendo asimismo el derecho al respeto de la decisión de tener o no un hijo" (apartado 57).

A poco de cumplirse un mes de la sentencia para el caso Evans, el Tribunal vuelve a pronunciarse para el caso Dickson contra Reino Unido ${ }^{8}$, y de nuevo se pone de manifiesto la flexibilidad del artículo 8 . Si bien en este caso, a mi entender, se incorpora un nuevo condicionante que también afectará a la modulabilidad del precepto. Las obligaciones positivas exigibles al Estado, a la luz del artículo 8 , además de depender del caso concreto y la propia regulación que se realice en cada Estado, también dependen de las "prioridades y recursos del Estado", aspectos que son de especial importancia por las peculiaridades del caso.

Puesto que el asunto no se resuelve a favor del demandante recurre ante la Gran Sala ${ }^{9}$, que aludiendo al caso Evans y otros anteriores, afirma de manera rotunda que denegar la inseminación artificial sí afecta a la vida privada y familiar

6 Apartado 61 de la sentencia. También encontramos en dicho apartado un interesante repertorio de jurisprudencia que se refiere a la inclusión en el artículo $8^{\circ}$ de los aspectos descritos.

7 Evans contra Reino Unido (2006): Sentencia Tribunal Europeo de Derechos Humanos Estrasburgo (Sección 4), de 7 marzo 2006 (TEDH 2006\19). En este caso una pareja se somete a fecundación in vitro, llevando a cabo la fecundación de un total de 6 embriones. Antes de la implantación de los mismos, la pareja rompe, y el que sería futuro padre revoca su consentimiento y pide que dichos embriones sean destruidos. Se trata de un caso especialmente dramático, pues la mujer, por problemas de salud, es sometida a una ovarotomía, por lo que esos óvulos fecundados son la única oportunidad que tiene para ser madre. Recurre al TEDH, alegando la vulneración de diversos artículos del Convenio, si bien la principal argumentación la encontramos respecto del art. 8 .

8 Dickson contra Reino Unido (2006): Sentencia Tribunal Europeo de Derechos Humanos Estrasburgo (Sección 4a), de 18 de abril de 2006 (TEDH 2006131). Se resuelve la petición de un preso, condenado por asesinato a cadena perpetua (cuya tiempo mínimo de cumplimiento se establece en 15 años) para poder inseminar a su mujer que se encuentra en libertad. La solicitud se basa en la imposibilidad de poder tener hijos de manera natural debido a la diferencia de edad que existe entre ellos, puesto que la mujer es 14 años más mayor, y la duración de la pena. Puesto que sus pretensiones no son satisfechas por los tribunales interiores, acude al TEDH alegando la vulneración del artículo 8 y el artículo 12 de Convenio.

9 Dickson contra Reino Unido (2007): Sentencia Tribunal Europeo de Derechos Humanos Estrasburgo (Gran Sala), de 4 de diciembre de 2007 (TEDH 2007\86). 
que protege el artículo 8, y que dicho precepto incluye la decisión de ser padres genéticos (apartado 66). La Gran Sala, sin embargo, da un paso más a lo estipulado por la Sala, pues considera que el artículo 8 no sólo incluye obligaciones negativas para el Estado, y que en este caso concreto se traduciría en determinar si se vulnera el derecho de los demandantes a concebir un hijo, sino que también puede incluir obligaciones positivas para el Estado, esto es, adoptar las medidas oportunas para que el derecho en cuestión pueda hacerse efectivo, y que en este caso supondría el permitir el acceso a técnicas que permitan engendrar un hijo (apartado 70). Otra cosa distinta es que existen o no motivos justificados para restringir tal derecho, pero a ello me referiré un poco más adelante.

En los siguientes años el Tribunal continúa con la misma línea interpretativa seguida en años anteriores, así en el caso S.H. y otros contra Austria ${ }^{10}$ recuerda que el artículo 8 del Convenio debe entenderse en un sentido amplio y que engloba diversas realidades que forman parte de la vida privada y familiar. En el apartado 60 de esta sentencia afirma de manera tajante que el uso de la procreación asistida médicamente con la intención de concebir un hijo forma parte del artículo 8 del Convenio "ya que esta elección es claramente una expresión de la vida privada y familiar".

La visión aperturista del TEDH en cuanto al artículo 8 no se ha detenido, muestra de ello es la sentencia dictada para el caso Costa y Pavan contra Italia ${ }^{11}$, en la que considero que el Tribunal da un paso más. Vuelve a reiterar, en el apartado 55, que el contenido del artículo 8 debe entenderse en sentido amplio y que en él se engloban otros aspectos relativos a la vida privada. Reconocido el derecho a ser padres y el derecho, en sentido positivo, de acceso a las técnicas de reproducción

10 S.H. y otros contra Austria (2010): Sentencia Tribunal Europeo de Derechos Humanos Estrasburgo (Sección 1a), de 1 de abril de 2010 (TEDH 2010 56). En esta ocasión la demanda procede de dos parejas que necesitan la donación de gametos para poder ser padres (en una se necesitan espermatozoides y en la otra óvulos). Deciden acudir conjuntamente ante el TEDH alegando que la regulación estatal al respecto, que prohíbe la donación de óvulos y la donación de esperma para fecundación in vitro, aunque sí la permite para inseminación artificial, es contraria al art. 14 (que prohíbe la discriminación) en relación al art. 8 del Convenio.

11 Costa y Pavan contra Italia (2012): Sentencia Tribunal Europeo de Derechos Humanos Estrasburgo (Sección 2a), de 28 de agosto de 2012 (TEDH 2012172). El caso que da origen a esta sentencia tiene ciertos elementos que lo diferencian de los vistos anteriormente. En esta ocasión se trata de una pareja fértil, pero portadores de fibrosis quística. Precisamente el hecho de que son portadores lo conocen tras tener a su primer hijo, que nace afectado por dicha anomalía. Se produce un segundo embarazo, pero al detectar la enfermedad en el feto, la pareja decidió abortar. Acuden al TEDH alegando que su ley estatal, cuando prohíbe las pruebas preimplantacionales y que las técnicas de reproducción asistida puedan ser utilizadas por parejas fértiles, atenta contra los artículos 8 y 14 del Convenio de Roma. 
asistida, parecía inevitable llegar a este momento, en el que no sólo se reconoce el derecho a tener hijos, sino que el Tribunal también afirma que forma parte de la vida privada y familiar, y por tanto del artículo 8, el uso de las técnicas de reproducción asistida y las pruebas preimplantatorias para intentar tener hijos que no estén afectados por anomalías que ya se saben padecen, o portan, sus padres (apartado 57). De ello cabe deducirse que el Tribunal entiende que dentro de los márgenes del artículo 8 no sólo se encontraría el derecho a tener hijos, sino también el derecho a tener hijos sanos.

$\mathrm{Al}$ margen de los asuntos analizados en este trabajo, resulta interesante señalar que esta flexibilización del artículo 8 también se ha producido para otros problemas jurídicos como la protección del medio ambiente. Como caso paradigmático se sigue presentando el de López Ostra contra España, que fue resuelto mediante la Sentencia 1998/2, y en la que el Tribunal considera que la vulneración del medio ambiente también supone una vulneración de la vida privada y familiar.

\section{EL AMPLIO MARGEN DE APRECIACIÓN OTORGADO A LOS ESTADOS}

También es tónica habitual en el TEDH que cuando se trata de asuntos relacionados con la bioética, otorga a los Estados un generoso poder de maniobra para que sean ellos los que decidan si regulan y cómo regulan el asunto.

Dicho margen de apreciación ya se pone de manifiesto abiertamente en el caso Frette contra Francia ${ }^{12}$, en el que se dilucida si un homosexual puede o no adoptar. En este caso el señor Frette, como demandante, alega ante el TEDH la vulneración de los artículos 8 y $14^{13}$, pues entiende que la negativa del Estado a la adopción de un hijo, además de atentar contra su vida privada, atenta contra la igualdad al considerar que está siendo discriminado por su orientación sexual.

El TEDH sienta las bases de algunos aspectos fundamentales respecto al artículo 14, afirmando que la diferencia de trato sólo resulta admisible si persigue un fin legítimo, y si existe proporcionalidad entre la medida que se adopta y ese fin que

12 Frette contra Francia (2002): Sentencia Tribunal Europeo de Derechos Humanos Estrasburgo, de 26 de febrero de 2002 (TEDH 2002/156). El señor Frette es soltero y homosexual, y se le deniega la adopción en Francia, a pesar de que en dicho país se permite para matrimonio y solteros. Decide acudir al TEDH por dicha denegación.

13 Artículo 14 Prohibición de discriminación

El goce de los derechos y libertades reconocidos en el presente Convenio ha de ser asegurado sin distinción alguna, especialmente por razones de sexo, raza, color, lengua, religión, opiniones políticas u otras, origen nacional o social, pertenencia a una minoría nacional, fortuna, nacimiento o cualquier otra situación. 
se persigue. Aunque no podemos profundizar más en la cuestión, pues supondría alejarnos del objeto central de este artículo, efectivamente, el Tribunal considera que la negativa sí obedece a un fin legítimo: la protección de los derechos y seguridad del menor. En cuanto a si existe o no proporcionalidad, finalmente el Tribunal concluye que sí se respeta dicho principio en base a ciertas argumentaciones; una de ellas, la que aquí más nos interesa, el amplio margen de apreciación que se ofrece a los Estados en la regulación de estas cuestiones. Las autoridades francesas podían considerar que su derecho a adoptar estaba limitado por los derechos de los menores; se reconoce por el propio Tribunal los escasos estudios científicos, si bien sí afirma la división que existe entre la comunidad científica respecto a las consecuencias que puede tener en el menor el convivir con una pareja homosexual.

Ciertamente llama la atención la importancia que da el TEDH a la opinión de esta comunidad científica, de tal manera que su veredicto final da a entender claramente que la considera cualificada para adoptar las decisiones oportunas respecto al tema ${ }^{14}$. Ello nos indica claramente el margen amplio que se concede a las autoridades interiores para regular en la materia.

En el mencionado caso Pretty también reconoce este margen de apreciación, si bien aclara que puede variar dependiendo de la naturaleza de las cuestiones y la importancia de los intereses en juego. El propio apartado segundo del artículo $8^{\circ}$ del Convenio establece la no injerencia en el derecho por parte de los Estados, salvo que la misma esté prevista por el poder público. En esta misma sentencia se refiere el Tribunal a estas injerencias, recordando que sólo son admisibles si son necesarias en una sociedad democrática y que sean proporcionales al fin que se persigue.

Por tanto, el Tribunal reconoce dicho margen de apreciación si bien siempre estará sometido a su control y al respecto de las exigencias que marca el Convenio (apartados 68 y siguientes).

Sólo dos años después vuelve a ponerlo de manifiesto en la sentencia dictada para el caso Vo contra Francia ${ }^{15}$, en la que el Tribunal entiende que en determinados aspectos, como la consideración jurídica del embrión o cuándo se considera iniciada la vida, se debe otorgar al Estado un margen de apreciación, siendo dos

14 Este mismo sentido, y respecto a este tema concreto, puede consultarse MARTín (2008), pp. 276 y ss.

15 Vo contra Francia (2004): Sentencia Tribunal Europeo de Derechos Humanos Estrasburgo (Gran Sala), de 8 julio 2004 (TEDH 2004152). La señora Vo acude a una revisión ginecológica en su sexto mes de embarazo. En la sala de espera de la consulta también hay otra señora Vo que acude para que la retiren un DIU. Cuando el médico llama a la señora Vo, refiriéndose a la última, entra a consulta la primera, y cuando el médico intenta retirarle el DIU provoca la ruptura de la bolsa de líquido amniótico. Finalmente, le deben provocar un aborto terapéutico, pero no consiguen mantener con vida al bebé. 
los motivos principales que llevan al Tribunal a tal consideración: $1^{\circ}$ son asuntos que no suelen estar totalmente definidos en el seno del propio Estado y $2^{\circ}$ no suele existir un consenso europeo sobre el tema (apartado 82).

En los asuntos relativos a la reproducción asistida, al igual que en los casos expuestos anteriormente, también se reconoce la libre apreciación de los Estados. Así lo manifiesta el Tribunal en el caso Evans contra Reino Unido, reconociendo que no existe un consenso europeo en cuanto a la regulación en la materia y mientras algunos Estados no han regulado, otros sí lo han hecho, aunque de manera diversa. Como apuntamos anteriormente el asunto central de este caso se refiere a la revocación del consentimiento, y el Tribunal entiende que la regulación que realiza el Estado, permitiendo la revocación hasta el momento de la implantación, sí supone una injerencia en la vida privada y familiar y, por tanto, en el artículo 8 , aunque se trata de una injerencia admisible, pues obedece a consideraciones de orden público imperiosas (apartados 58 y siguientes). Nos encontramos, por tanto, ante una intromisión que si bien afecta al artículo 8 no lo vulnera, pues entraría dentro del ámbito de apreciación del Estado.

En el apartado 68 reconoce el Tribunal que al elaborar la ley podían haberse ponderado los intereses en juego de otra forma, pero también aclara que no es labor suya analizar si el Parlamento tenía otra posibilidad, sino determinar si cuando legisló lo hizo más allá del margen de apreciación que le corresponde. Finalmente, considera que el Reino Unido no se excede del ámbito previsto a la hora de legislar.

En el caso Dickson contra Reino Unido vuelve el Tribunal a referirse al amplio margen de apreciación de los Estados, aludiendo no sólo a la disparidad de opiniones existentes en los mismos respecto al tema, sino a las prioridades y recursos con los que cuenta cada uno, como ya aludíamos anteriormente. La Gran Sala se reitera en esta apreciación, considerando que son las autoridades internas las que mejor conocen a sus habitantes y sus necesidades. El Tribunal sólo estaría habilitado para intervenir cuando exista un "fundamento manifiestamente irrazonable" (apartado 78).

En la sentencia pronunciada para el caso S.H. y otros contra Austria, en los apartados 68 y 69 de la misma, vuelve a hacer referencia al margen de apreciación de los Estados. Si bien no existe obligación para ninguno el regular respecto a reproducción asistida, cuando lo hacen son diversas las técnicas que se recogen, prohibiéndose algunas y permitiéndose otras, sin que exista uniformidad de criterios entre las diversas legislaciones interiores. Concede el Tribunal, por tanto, un amplio margen de apreciación a los Estados, si bien en este caso, como en los anteriores, analiza si la elección adoptada por el Legislativo austriaco está dentro de los márgenes que marca el Convenio. 
Algunos autores hablan de relación de reciprocidad inversa, entre el margen de apreciación de los Estados y la teoría del consenso ${ }^{16}$, esto es, cuanto más consenso hay en la regulación de un tema por parte de los Estados, menos margen de actuación tienen éstos. En el tema que nos ocupa, el propio Tribunal reconoce que existe poca uniformidad en cuanto a la regulación, ni siquiera la hay en cuanto a la consideración jurídica del nasciturus, por ello, entiende el Tribunal, que el margen de apreciación para el Estado miembro debe ser mayor.

Como estamos viendo, y tendremos oportunidad de seguir haciendo al hilo de algún caso concreto, la labor del Tribunal no se centra en enjuiciar la norma interna en cuanto a su fondo, sino más bien, en base a ese margen de libre actuación que se le da al Estado, el principal trabajo que le ocupa es analizar si la regulación nacional estaría o no dentro de los límites del Convenio. Sin embargo, esta tarea parece ampliarse con la llegada de la Sentencia dictada para el caso Costa y Paván, pues como veremos no se limita al análisis descrito, sino que va un poco más allá y es capaz de afirmar que la ley italiana es incoherente. Algunos autores han hecho referencia a este cambio cualitativo que se produce con el caso italiano, es el caso de Arias Aparicio, que no sólo reconoce este avance en la interpretación del Tribunal, sino que afirma que esto podría suponer una vulneración de ciertos intereses privados ${ }^{17}$.

Resulta interesante señalar como un criterio ampliamente admitido y usado por el TEDH no lo ha sido por la Corte Interamericana de Derechos Humanos. En el conocido caso Artavia Murillo y otros contra Costa Rica, aunque se discute un asunto sobre el que no existe homogeneidad en cuanto a su tratamiento, esto es, la consideración jurídica del nasciturus, y a pesar de que el Estado costarricense alega expresamente el criterio del margen de apreciación nacional, finalmente, la Corte omite la aplicación de dicha doctrina.

\section{Problemáticas concretas resueltas por el Tribunal}

\section{La revocación del consentimiento}

tras la fecundación in vitro pero antes de la implantación

Este es precisamente el asunto que se suscita en el reiterado caso Evans contra Reino Unido. La legislación del Estado en la materia permite la revocación del consentimiento una vez realizada la fecundación, pero siempre antes de que se

16 Es el caso de Penasa (2013).

17 ARIAS (2014), p. 18. 
produzca la implantación. Como se explicó en un momento anterior, la pareja rompe y es el hombre el que decide revocar su consentimiento, siendo la mujer la que demanda ante el TEDH, pues entiende que dicha disposición interna vulnera los artículos 8 , el 14 y el $2^{18}$ del Convenio.

El Tribunal da especial relevancia al requisito del consentimiento, prestado en el documento firmado por la pareja antes de comenzar las técnicas, considerando que obviarlo para el caso del varón, o entenderlo como no decisivo, supondría no reconocer los respectivos derechos de los interesados, además de que se provocarían otros problemas jurídicos por arbitrariedad e incoherencia (apartado 65).

No confirma las pretensiones de la mujer, pues como vimos, entiende el Tribunal que entra en el margen de discrecionalidad del Estado la regulación sobre la materia, y que la forma en cómo lo hace el Reino Unido, al establecer que el consentimiento se puede revocar hasta el momento de la implantación del embrión, es conforme al artículo 8.

Además de que no existe un consenso internacional sobre la cuestión de hasta qué momento puede revocarse el consentimiento a la utilización de los gametos, la forma en cómo lo regula el Reino Unido es plenamente admisible, diciendo que "insertando en la Ley de 1990 una disposición clara basada en consideraciones de principio, que reconoce a cada una de las personas afectadas por un tratamiento de FIV la libertad de retractarse hasta el momento de la implantación del embrión, que fue explicada a los participantes en el tratamiento en cuestión y que figuraba explícitamente en los formularios que éstos firmaron, el Reino Unido no ha excedido el margen de apreciación de que dispone ni ha roto el equilibrio exigido por el artículo 8 del Convenio" (apartado 69).

Dicha argumentación nos indica que también estaría dentro de los límites posibles una regulación distinta, por ejemplo, que permitiera la revocación sólo hasta el momento de la fecundación del óvulo, en vez de la implantación del mismo, o que se permitiese la revocación, salvo circunstancias muy concretas como las que se dan en este caso (que la mujer ya no podrá ser madre) ${ }^{19}$; todo ello nos indica claramente la apertura que se produce en la posible interpretación del artículo 8, como quedó expuesto en páginas anteriores.

\footnotetext{
18 Artículo 2 Derecho a la vida
}

1. El derecho de toda persona a la vida está protegido por la ley. Nadie podrá ser privado de su vida intencionadamente, salvo en ejecución de una condena que imponga pena capital dictada por un tribunal al reo de un delito para el que la ley establece esa pena.

19 De hecho este es el argumento utilizado por dos jueces que dictan votos particulares a la sentencia, como veremos más adelante. 
Además de alegar el artículo 8 del Convenio, la demandante también entiende que la legislación del Reino Unido atenta contra el artículo 14, pues considera que la mujer que puede tener hijos de manera natural, sin necesidad de ayuda médica, puede elegir el destino que quiere dar a sus óvulos fecundados, mientras que la mujer que se somete a técnicas de reproducción asistida depende de los intereses del varón que dona el esperma.

Recuerda el Tribunal en el apartado 73 que "a efectos del artículo 14, una diferencia de trato entre personas en situaciones análogas o comparables es discriminatoria si no se basa en una justificación objetiva y razonable, es decir, si no persigue un fin legítimo o si carece de relación razonable de proporcionalidad entre los medios empleados y el fin perseguido". También para este caso se considera que será el Estado el que tenga margen para apreciar qué diferencias justificarían un trato distinto de supuestos análogos. Asimismo, recuerda el Tribunal que en la sentencia para el caso Pretty dijo que también podría ser discriminatorio el supuesto contrario, es decir, no dar un trato diferente a situaciones que son diferentes.

Concluye el Tribunal afirmando que los mismos argumentos utilizados para entender que no se vulnera el artículo 8, sirven para apreciar que no se ha producido vulneración del artículo 14.

Junto a los preceptos anteriores, también alega la demandante una vulneración del artículo 2 que protege el derecho a la vida, pues entiende que admitir la revocación de su ex pareja y permitir la destrucción de los embriones atenta contra el citado artículo del Convenio, ya que la vida de los mismos se deja únicamente en manos de sus progenitores. El TEDH se enfrenta en este punto a la concepción jurídica del embrión o del feto, y para ello se remite a la sentencia dictada para el caso Vo. Vuelve a poner de relieve la falta de consenso con respecto al tema, y aunque merecedor de cierta protección, afirma que el Tribunal no puede decidir en abstracto y con carácter general para todos los Estados que un no nacido puede ser considerado persona. Especialmente crítica con este aspecto se muestra Albert, pues considera que en el contexto europeo se produce discriminación en la forma en cómo se concibe al embrión preimplantatorio, afirmando que si no se protege la vida en el caso Vo cuando se trata de un feto de 6 meses, mucho menos en el caso Evans que se trata de embriones sin implantar ${ }^{20}$.

En este caso la argumentación del TEDH no fue coincidente entre todos sus jueces, pues dos de ellos, el señor Traja y la señora Mijovic, plantearon una opinión

20 La crítica se produce a lo largo de todo el texto, especialmente en lo que respecta al TEDH, p. 480. Albert (2013), p. 480. 
disidente. Consideran que dar un valor absoluto a la revocación de una de las partes, provoca que la otra parte pierda cualquier poder de decisión al respecto. Consideran que deberían haberse ponderado los intereses particulares en juego.

Se trata de una interpretación muy parecida a la dada por el Tribunal Supremo israelí para el caso Nachmani contra Nachmani ${ }^{21}$ en la que los jueces dan prioridad al derecho de la mujer a ser madre, cuando esa es la única oportunidad que tiene para serlo. Ciertamente debe advertirse que la gran diferencia entre el caso israelí y el británico, es que en Israel no existe una ley que regule dicho consentimiento, ni la partes habían firmado un documento con tales exigencias.

Evidentemente la respuesta dada por el Tribunal no satisface a la mujer, que decide recurrir ante la Gran Sala, la cual se pronuncia a través de una sentencia de abril de $2007^{22}$. Vuelve a poner de manifiesto el margen de apreciación de los Estados, y considera que cuando la ley inglesa permite la revocación absoluta a una de las partes es para proteger el orden público. Se vuelve a mencionar la importancia del consentimiento prestado y el hecho de que ambas partes sabían de manera previa la existencia de la posibilidad de revocación.

También se emiten opiniones disidentes en este caso, en el mismo sentido que las realizadas en la sentencia recurrida. Se deberían haber tenido más en cuenta las circunstancias concretas del caso, pues la aplicación de la ley en este supuesto protege de manera absoluta a una de las partes y desampara por completo a la otra.

Ciertamente las circunstancias de este caso, esencialmente el hecho de que la mujer padezca una enfermedad que la impide tener hijos en el futuro, hacen que la complejidad del caso aumente. Mientras que el TEDH, como posteriormente la Gran Sala decide aplicar de manera estricta la ley inglesa, las opiniones discrepantes en ambos casos se inclinan por entender que se debería haber ponderado teniendo en cuenta las especiales circunstancias del caso. Así lo considera Serna Meroño, afirmando que para supuestos tan complejos no pueden utilizarse criterios generales, y que deberían tenerse en cuenta las circunstancias concretas del caso, por ejemplo, en este supuesto quizá debieran establecerse excepciones a la regla general de la revocabilidad ${ }^{23}$. Por su parte, Farnós entiende que puesto que nos encontramos ante una cuestión trascendental, y la regulación de los Estados no

21 50(4) P.D. 661 (Isr. 1997).

22 Evans contra Reino Unido (2007): Sentencia Tribunal Europeo de Derechos Humanos Estrasburgo (Gran Sala), 10 de abril de 2007.

23 SERna (2012), p. 279. 
prevé qué ocurre en caso de ruptura de la pareja, el TEDH debería pronunciarse respecto a los límites que deberían establecerse a los pactos realizados por la pareja y el destino que debe darse a los preembriones ${ }^{24}$.

Como se ha visto, es el propio TEDH el que en reiterada jurisprudencia afirma que en este tipo de supuestos, vinculados a la bioética, los Estados deben gozar de un amplio margen de apreciación. Puesto que esta es la línea argumentativa seguida por el Tribunal, personalmente considero que la decisión adoptada por el TEDH es la más coherente con la propia orientación que ha decidido seguir. La Corte de Estrasburgo no obliga a los Estados a que regulen en materia de reproducción asistida; pero si lo hacen, entiendo que la única labor posible en estos casos es analizar si la regulación estatal es acorde a los márgenes establecidos en el Convenio -que no se produzca discriminación y que se tengan en cuenta los intereses implicados- y de ser así no cabe otra solución que respetar lo estipulado por los Estados al respecto. El Tribunal decide adoptar una posición neutral y de respeto hacia las legislaciones nacionales, sin pasar a valorar si la misma es la más adecuada. De hecho, como el propio Tribunal reconoce, la regulación al respecto, y concretamente la que se refiere a la revocación del consentimiento, varía de un Estado a otro, por lo que lo más coherente, si dichas regulaciones respetan el Convenio, es que se apliquen tal y como están estipuladas.

Sin embargo, aun partiendo de esta hipótesis, que a priori parece la más coherente con la línea seguida por el Tribunal, las excepciones son posibles, en algunos casos necesarias, pues establecer un poder de revocación absoluto siempre anula cualquier margen de maniobra en la otra parte, por muy extrema o dramática que sea la circunstancia ${ }^{25}$, pero entiendo que dichas excepciones deberían venir establecidas desde el ámbito interno, no siendo el TEDH el adecuado para establecerlas.

Quizá lo más conveniente sería, como afirma Farnós, que dado que el número es cada vez mayor, tanto de divorcios como de parejas que acuden a estas técnicas, que los Estados fijaran claramente cuál debería ser el destino de los embriones en caso de desacuerdo, y que pudieran preverse excepciones a la revocación del consentimiento ante circunstancias especiales como las que se dan en este caso ${ }^{26}$.

24 FARNÓs (2007 a)), p. 14.

25 En este sentido, Alkorta afirma que "en la mayoría de los casos analizados se observa que la revocación del consentimiento se ha convertido en un derecho de veto por parte del varón a la implantación de los embriones solicitada por la mujer", en AlKORTA (2006), p. 59.

26 FARNós (2007 b), p. 6. 


\section{Solicitud de un preso para inseminar a su mujer que se encuentra en libertad}

Como ya apuntamos anteriormente este es el supuesto que se produce en el caso Dickson contra Reino Unido. El Tribunal reconoce que salvo el derecho de libertad, los reclusos no pierden el resto de derechos que otorga el Convenio, pero sí matiza que debido a la situación especial de un privado de libertad, algunos de los derechos sí pueden verse afectados y controlados. La Sala reconoce que los requisitos impuestos por la legislación interna a la hora de conceder o no una solicitud como la que se analiza en la sentencia, son razonables, pues se establecen para salvaguardar dos objetivos: mantener la confianza en el sistema sanitario y garantizar el bienestar del futuro hijo. Se consideró que la decisión adoptada por los tribunales interiores no era irracional o desproporcionada, ni que se rompía el equilibrio justo entre los intereses implicados, atendiendo a las circunstancias concretas del caso, por todo ello entendió el TEDH que no se vulneraba ninguno de los dos artículos alegados, ni el 8 ni el $12^{27}$.

También coincide la Gran Sala con esta misma afirmación, recordando la sentencia dictada para el caso Hirst contra Reino Unido ${ }^{28}$. En ella se analizaba el derecho a voto de los reclusos, y se recordaba amplia jurisprudencia anterior respecto a otros derechos ejercidos por presos, tales como la libertad de expresión, la libertad religiosa o la integridad física, y que en todo caso coinciden en afirmar que cualquier restricción en los derechos del recluso debe estar justificada. La mera existencia de una condena no es motivo suficiente para privar al recluso de sus derechos (apartados 67 y 68).

Como se comentara unas páginas más arriba, la Gran Sala alude a la diferencia entre las obligaciones positivas y negativas del Estado, si bien considera que en este caso lo relevante es determinar si dichas obligaciones no fueron atendidas de manera justificada y, por tanto, no se ha producido una ruptura en el justo equilibrio entre los intereses privados y los públicos.

En cuanto a los privados se refiere, básicamente, a que la solicitud de inseminación es la única posibilidad para la pareja de poder tener hijos en común, debido a la edad de la mujer y los años impuestos por la condena.

27 Artículo 12 Derecho a contraer matrimonio

A partir de la edad núbil, el hombre y la mujer tienen derecho a casarse y a fundar una familia según las leyes nacionales que rijan el ejercicio de este derecho.

28 Hirst contra Reino Unido (2005): Sentencia Tribunal Europeo de Derechos Humanos Estrasburgo, de 6 de febrero de 2005 (TEDH 2005\103). 
Respecto a los intereses públicos, el Gobierno considera que aceptar la petición de los demandantes y permitir que el culpable de un delito grave pueda tener hijos, supondría poner en entredicho la confianza que tiene la sociedad en el sistema penitenciario, además de que la restricción puede entenderse como un castigo por la privación de libertad. También se pone de manifiesto los perjuicios que se podría ocasionar al hijo por no poder tener a su lado a uno de sus progenitores por un período tan largo de tiempo.

La Gran Sala no comparte las argumentaciones del Gobierno: por una parte entiende que la confianza de la sociedad en las instituciones penitenciarias es crucial, pero no se puede privar al recluso de sus derechos simplemente porque eso pueda disgustar a la sociedad, además de que las penas, recuerda el Tribunal, esencialmente tienen una finalidad de reinserción, no de castigo. En cuanto a la protección del futuro hijo, la Gran Sala considera acertada la preocupación mostrada, pero ello no justifica que se impida a los padres poder tener descendencia, máxime cuando la madre sí está libre y puede hacerse cargo de su hijo (apartados 72 y siguientes).

Contraviniendo lo dicho por la Sala, y aun admitiendo el amplio margen de apreciación de los Estados en este caso, la Gran Sala considera que se ha sobrepasado dicho margen. No ha existido una adecuada ponderación entre los intereses privados y los públicos, entendiendo que las restricciones son desproporcionadas y, por tanto, vulneradoras del artículo 8 del Convenio.

Interesante es la opinión disidente de cinco de los jueces miembros de la Gran Sala, que consideraron que sí se realizó una correcta ponderación entre los intereses implicados y coinciden con la opinión del Gobierno inglés. No consideran que las autoridades interiores actuaran de manera arbitraria o desproporcionada, a la vista de los elementos característicos de este caso: que nunca hubo convivencia de la pareja en libertad, la gravedad del delito y de la pena impuesta, la avanzada edad de la mujer que además hubiera dificultado el éxito de las técnicas y la protección del menor ante la ausencia de figura paterna durante muchos años, entre otros.

\section{La prohibición de donación de óvulos y esperma para la fecundación in vitro (si bien esta última si está permitida cuando se trata de inseminación artificial)}

Este asunto fue analizado en el caso S.H. y otros contra Austria. La demanda presentada para este caso gira en torno al artículo 14 del Convenio pues las parejas consideran que la legislación interna, al permitir la donación de esperma para inseminación artificial, pero prohibir dicha donación y la de óvulos cuando 
se trata de fecundación in vitro, les provoca una diferencia de trato injustificada respecto de otras parejas, y por tanto una discriminación.

El Tribunal reitera en el apartado 64 lo dicho en otras ocasiones anteriores, que para entenderse como discriminatoria la diferencia de trato no debe basarse en una justificación objetiva y razonable. Considera apropiado analizar cada uno de los casos por separado, a pesar de tratarse de una única demanda.

Una de las parejas necesita la donación de óvulos para una fecundación in vitro, pues la enfermedad que padece la mujer le impide poder crearlos, si bien su útero está en perfecto estado y los espermatozoides de su marido también. La legislación interna prohíbe la donación de óvulos en estos casos, pero sí permite que otras parejas, con otras dolencias distintas pero que no necesitan óvulos de terceras personas, puedan utilizar las técnicas de reproducción asistida. Debe valorar el Tribunal si la diferencia de trato está o no justificada y si es proporcional al fin que se persigue.

Las medidas impuestas por el legislador interno tratan de justificarse alegando esencialmente cinco aspectos: 1) que deben protegerse ciertos sectores sensibles de la sociedad, que se muestran reticentes a la existencia y uso de estas técnicas, 2) los riesgos que puede provocar la fecundación in vitro si se utiliza para otros fines distintos del terapéutico o si se utiliza a mujeres con el único fin de conseguir sus óvulos, 3) los riesgos médicos que comporta la donación de óvulos, 4) permitir ese tipo de fecundación heteróloga provocaría relaciones familiares inusuales al dividirse la maternidad y 5) la imposibilidad de permitir a los hijos poder conocer sus ascendentes reales.

En cuanto a la primera de las interpretaciones, el Tribunal afirma que las consideraciones morales no son justificación suficiente para impedir de manera absoluta una determinada técnica como es la donación de óvulos. Los Estados no están obligados a regular respecto a estas técnicas, pero si lo hacen deben mantenerse dentro de los límites del Convenio y sujetos al escrutinio del Tribunal (apartado 74). En cuanto a la segunda, el Tribunal acepta la existencia de posibles riesgos, pero afirma que debe ser el Estado el que realice un análisis exhaustivo de los mismos y adoptar las medidas más adecuadas para el justo equilibrio entre intereses públicos y privados. Considera que la prohibición absoluta no es la única ni mejor solución para conseguir tal equilibrio (apartados 76 y 77). La tercera argumentación tampoco es admitida por el Tribunal, pues alega que la fecundación homóloga sí se permite y también se realiza la extracción de óvulos con un riesgo similar (apartado 78). La cuarta interpretación tampoco convence al Tribunal, pues matiza que las relaciones inusuales no es algo nuevo y su existencia no es 
óbice para prohibir de manera absoluta este tipo de técnicas (apartado 81). El último de los argumentos nuevamente sería rechazado, pues el derecho a conocer los antecedentes familiares no es absoluto y puede ceder para salvaguardar otros intereses en juego (apartados 83 y 84).

En el segundo de los supuestos, además de que la mujer padece una enfermedad en las Trompas de Falopio, los espermatozoides del marido no son adecuados para producir un embarazo. La única solución posible para su caso es la donación de esperma de un tercero, y realizar una fecundación in vitro, técnica prohibida en Austria, si bien sí se permite la donación de esperma para inseminación artificial.

En este caso, el Tribunal debe valorar si la diferencia de trato otorgada a una pareja que necesita fecundación in vitro y la que necesita fecundación in vivo se basa en razones objetivas y proporcionadas.

Desde el Estado vuelven a utilizarse argumentos como el riesgo de usar las técnicas con fines distintos del terapéutico y la dificultad del hijo para conocer su descendencia real. Pero, además, se alude por parte del Gobierno austriaco a que la donación se permite para inseminación artificial porque se trata de una técnica ya usada hace muchos años, si bien la fecundación in vitro es mucho más reciente y novedosa.

Las medidas impuestas por la legislación austriaca a la luz de lo dispuesto por el Tribunal vulneran el artículo 14 en relación con el 8. La prohibición absoluta de las técnicas es desproporcionada, no habiéndose realizado una correcta ponderación entre los intereses públicos y los privados. Los motivos alegados no son razón suficiente ni justifican la desigualdad de trato. Precisamente, esta argumentación del Tribunal provoca que algunos autores entiendan que nos encontramos ante una sentencia especialmente relevante. Vidal Martínez considera que marca un punto de inflexión en la regulación europea, pues supone un reproche al establecimiento de prohibiciones absolutas en lo que a técnicas de reproducción asistida se refiere ${ }^{29}$.

También encontramos en la sentencia opiniones disidentes. Una parcialmente, la del juez Steiner, que si bien coindice con la sentencia en cuanto al segundo caso, no opina lo mismo en cuanto al primero, considerando que la prohibición de donación de óvulos no vulnera el artículo 14. Más crítica es la opinión disidente del juez Jebens, pues además de que considera que son de aplicación independiente los artículos 8 y 14, considera que si bien se ha producido un

29 VidAL (2011), pp. 184 y 185. 
trato distinto, ello obedece a que los casos no son similares, sino que también responden a situaciones distintas. No observa, por tanto, que se haya producido una vulneración del artículo 14 .

A pesar de que el Tribunal considera que el Convenio ha sido vulnerado, y se condena a Austria por ello (aunque veremos que la Gran Sala da un giro total a la interpretación del asunto), vuelve a ponerse de manifiesto el amplio margen de actuación que se da a los Estados en la materia, la posibilidad que tienen de decidir si regulan o no sobre la reproducción asistida, y de hacerlo, la libertad de regular de la forma que consideren más apropiada, si bien es cierto que la labor del Tribunal en este caso será corroborar que efectivamente dicha legislación no se opone a las previsiones del Convenio. Todo ello nos lleva a entender que para el TEDH el sometimiento a las técnicas de reproducción asistida no puede entenderse como un derecho fundamental en todo caso, generador de obligaciones positivas y negativas para el Estado. En este mismo sentido se pronuncia Vidal Martínez, quien tras analizar esta sentencia, conjuntamente con las dictadas para los casos Evans y Dickson contra Reino Unido, considera que los ciudadanos tienen derecho a no sufrir interferencias arbitrarias en el disfrute de su vida privada y familiar, en lo cual se incluye el sometimiento a las técnicas de reproducción asistida; sin embargo, piensa que ello no implica que se genere una obligación positiva para el Estado, en cuanto a proporcionar los medios para acceder a dichas técnicas como alternativa a la libertad de procrear $^{30}$.

Con este pronunciamiento parece que tratan de fijarse unos criterios claros sobre las técnicas de reproducción asistida en Europa; sin embargo, la sentencia de la Sala acaba siendo recurrida ante la Gran Sala, y cuyo pronunciamiento provoca un cambio radical de criterio respecto al asunto.

Las argumentaciones del Gobierno que tan insuficientes le parecieron a la Sala, fueron especialmente relevantes para la Gran Sala, que el 3 de noviembre de 2011 dicta una sentencia sorprendente en la que se rebate todo lo dicho en el pronunciamiento anterior ${ }^{31}$. Efectivamente, el Tribunal reconoce que se deriva del artículo 8 de la Convención el derecho a ser padres, aun siéndolo a través de técnicas de reproducción asistida, incluida la heteróloga, si bien vuelve a ponerse de manifiesto el amplio margen de maniobra que el Tribunal concede a los Estados. Reconoce que la fecundación heteróloga tiene una amplia consideración por parte

30 Vidal (2011), pp. 185 a 187.

31 S.H. y otros contra Austria (2011): Sentencia Tribunal Europeo de Derechos Humanos Estrasburgo (Gran Sala), de 3 de noviembre de 2011. 
de los Estados; sin embargo, también afirma que cuando se trata de fecundación heteróloga in vitro, los elementos morales y éticos están más presentes.

Considera que la regulación austriaca no es excesivamente restrictiva, pues permite la reproducción asistida, incluso la heteróloga en algunos casos. La diferencia de trato que establece el legislador está justificada pues están implicados numerosos elementos morales, y la ley trata de minimizar los posibles conflictos sociales al respecto, y por otra parte, el legislador trata de hacer posible la aplicación de la reproducción asistida.

Como todos los pronunciamientos, la sentencia de la Gran Sala consigue opiniones favorables, y otras no tanto; sin embargo, más allá del aspecto jurídico concreto, y los motivos alegados para rebatir la sentencia anterior, uno de los aspectos curiosos es que la propia sentencia realza, de manera expresa, el hecho de que la legislación austriaca no prohíbe el que las parejas puedan ir a otros Estados a someterse a técnicas que en Austria no están permitidas, y que los hijos fruto de estas técnicas tendrán un adecuado reconocimiento jurídico en Austria. Esta aseveración ha sido fuertemente criticada, pues fomenta abiertamente el turismo reproductivo ${ }^{32}$.

\section{La probibición de las pruebas preimplantacionales}

Esta situación es la que se produce en el caso Costa y Pavan contra Italia. La legislación italiana prohíbe el uso de las técnicas de reproducción asistida a parejas que son fértiles, así como las pruebas genéticas preimplantatorias. Realizadas las precisiones de contenido del artículo 8, que vimos en unas páginas anteriores, entiende el Tribunal que dicha prohibición supone una injerencia en la vida privada y familiar de las personas.

Para los recurrentes resulta contradictorio que no se permitan pruebas previas a la implantación, con el objetivo de analizar si el embrión porta o no la enfermedad, pero sí se prevea la interrupción voluntaria del embarazo. Las autoridades internas, por su parte, defienden las medidas prohibitivas alegando que se trata de proteger la salud de la madre y del hijo, de garantizar la objeción de conciencia del personal sanitario, así como evitar un riesgo hacia la eugenesia.

Los argumentos del Gobierno no convencen al TEDH que no entiende cómo se trata de proteger al embrión prohibiendo las pruebas cuando sí se permite el aborto de un feto que está más desarrollado, además de los problemas que un

32 Un ejemplo de esta crítica lo encontramos en FARNós (2011), p. 64. 
aborto comporta para la pareja y sobre todo para la salud de la madre (apartados 62 y 63). En cuanto al derecho a la objeción de conciencia, o los riesgos de eugenesia, también pone de manifiesto el Tribunal que el Gobierno no explica nada de estos aspectos respecto a la interrupción voluntaria del embarazo.

En los apartados 64 y siguientes el Tribunal manifiesta su desacuerdo con la legislación italiana y su falta de coherencia impidiendo tales pruebas, pero sí permitiendo un aborto en una fase posterior. También reconoce la Corte que si se compara la regulación italiana con la de otros Estados de su entorno, la posición adoptada en Italia es minoritaria. Finalmente considera que la prohibición de pruebas preimplantatorias sí vulnera el artículo 8.

Sólo cabe destacar, además de lo acertado de la sentencia, a mi modo de ver, que se trata de una opinión unánime, pues no se realizaron opiniones disidentes en este caso.

Como apuntaba en un momento anterior, cabe considerar que desde el momento en que la fecundación asistida se abre por los jueces a parejas fértiles, pero con la finalidad de prever posibles enfermedades en el embrión antes de implantarlo, debemos entender que el derecho a procrear no sólo incluye el derecho a tener un hijo, sino que también implica el derecho a tenerlo sano. Aquí no estamos hablando de tener hijos a la carta, y poder elegir el sexo o el color de los ojos, estamos hablando de evitar el riesgo, en muchos supuestos casi cierto, de que nazca un niño enfermo y conseguir que pueda nacer sano.

También es interesante resaltar el paso cualitativo que da el TEDH con este pronunciamiento, pues no sólo se limita a comprobar si la legislación interna es acorde a lo estipulado por el Convenio, como venía siendo habitual en sus sentencias, sino que de manera clara pasa a analizar el fondo del asunto y afirma con rotundidad la falta de coherencia de la regulación italiana en este asunto.

\section{La adopción (y reproducción asistida) en parejas homosexuales}

Hasta el momento el TEDH no ha resuelto ningún asunto relativo a reproducción asistida cuando se trata de una pareja o una persona homosexual, al menos como asunto principal. Sí aparece dicho asunto, aunque de manera secundaria, en la sentencia pronunciada para el caso Gas y Dubois contra Francia ${ }^{33}$. Se trata de dos mujeres que son pareja desde hace once años y deciden tener hijos. La

33 Gas y Dubois contra Francia (2012): Sentencia Tribunal Europeo de Derechos Humanos Estrasburgo (sección 5a), de 15 de marzo de 2012 (TEDH 2012/108). 
señora Gas se somete a técnicas de fecundación asistida en Bélgica con semen de un donante y da a luz en Francia a una niña. Tras su nacimiento deciden formalizar su situación de pareja, suscribiendo un Pacto Civil de Solidaridad y la señora Dubois solicita la adopción simple de la niña que había tenido su pareja. Finalmente, la solicitud de adopción es denegada por el TEDH.

En lo que respecta a la reproducción asistida, solamente recalcar que dichas técnicas se realizaron fuera de Francia, concretamente en Bélgica, y que la niña que nace fruto de las mismas es registrada sin ningún problema en un registro público francés, aunque la normativa interna sólo prevé este tipo de técnicas para matrimonios heterosexuales y con una finalidad terapéutica.

\section{COnclusiones}

Ciertamente se trata de un tema muy heterogéneo y complejo, como suele ser habitual en todos aquellos en los que interviene la vida, la salud, la dignidad o la integridad. Más si cabe cuando el conflicto se produce como consecuencia del avance científico y la repercusión que éste puede tener en los citados derechos.

Como ya se indicara al inicio de este trabajo, y que se pone claramente de manifiesto tras el análisis de los diversos pronunciamientos del TEDH, no existe homogeneidad entre los Estados miembro en cuanto a la regulación de esta materia, aunque también es reconocido por el Tribunal el amplio margen de discrecionalidad que se le da al Estado para regular.

Por ello considero de especial importancia el papel jugado por el Tribunal, como moderador de todo este conflicto, y armonizador de las diversas posiciones al respecto. Se reconoce un margen amplio al Estado, pero cuando el Estado decide regular, es cuando el Tribunal debe velar porque esa regulación sea acorde al Convenio, tratando de marcar una pautas básicas que todos los Estados miembros deben cumplir.

Como también quedara apuntado, el derecho a la reproducción no está en el Convenio, por eso cobra especial relevancia la interpretación dada al artículo 8 y la flexibilidad que el propio Tribunal concede a su contenido.

Más allá de los supuestos concretos, cuando el TEDH se enfrenta a un asunto como la reproducción asistida basa sus argumentaciones en tres elementos clave: 1) La amplitud en los márgenes del artículo 8 , considerando que determinados supuestos se engloban dentro de la vida privada y familiar, aunque el precepto no lo diga expresamente; 2) El amplio margen que se otorga a los Estados para regular algunos supuestos en lo que no existe unanimidad de regulación; 3) Respeto por la decisión interna de regular o no cuestiones concretas. El Tribunal se 
muestra especialmente sensible con los asuntos más relacionados con la bioética, ante los cuales se muestra neutral en cuanto a la decisión del Estado de legislar o no. El verdadero trabajo comienza para el TEDH cuando el Estado sí decide regular, pues en ese caso, más que evaluar la forma concreta en cómo lo hace, garantiza que dicha regulación sea conforme a las estipulaciones que marca el Convenio de Roma.

Resulta evidente que tratar de buscar la homogeneidad de regulaciones en asuntos como el aquí tratado sería casi una utopía, pero ello no es óbice para que la labor del Tribunal no vaya encaminada a conseguir, en la medida de lo posible, unos estándares comunes para todos. Hasta el momento el Tribunal ha desarrollado su labor con una gran cautela, pero nos encontramos ante supuestos complejos, cuyo número va en aumento, y quizá la labor del TEDH debería ser más profunda. El respeto por el margen de apreciación que se ha otorgado a los Estados, y la falta de consenso en un tema difícil y tan relacionado con los derechos más esenciales, no pueden ser un límite para que el Tribunal reconozca abiertamente las posibles violaciones que las normativas internas provocan en el Convenio.

Aunque esto suele ser lo habitual en las interpretaciones del Tribunal, quizá no sea suficiente, y en algunos casos sea necesario adentrarse más en el fondo del asunto para impedir injerencias indebidas en derechos que cada vez más están presentes en nuestra sociedad. A veces son necesarias las apreciaciones concretas de cada caso, por ejemplo, en el supuesto de la revocabilidad que vimos para el caso Evans contra Reino Unido. Dar por válida la legislación interna y entender que se puede revocar el consentimiento en todo caso, puede provocar una protección excesiva para una de las partes e indefensión en la otra; por ello, en ocasiones especialmente complicadas quizá sería adecuado atender a las circunstancias concretas. Parece que este camino ya se ha iniciado por el TEDH con la sentencia pronunciada para el caso Costa y Paván, en el que no duda en entrar en el fondo del asunto y manifestar claramente la incoherencia de la ley italiana.

\section{BibLIOGRAFÍA CITADA}

Albert, Marta (2013): "El caso Brüstle v. Greenpeace y el final de la discriminación de los embriones preimplantatorios", en Cuadernos de bioética (XXIV 2013/3a), pp. 475-498.

AlKorTa Idiakez, Itziar (2006): "Nuevos límites del derecho a procrear", en Derecho privado y Constitución (No 20, enero-diciembre), pp. 9-61.

Arias Aparicio, Flor (2014): "El acceso a las técnicas de reproducción humana asistida como derecho: reconocimiento y protección en el marco del derecho 
a la vida privada”, en Revista General de Derecho Constitucional, Revistas@ iustel.com. (No 18), pp. 1-32.

FARnós Amorós, Esther (2007 a)): “¿De quién son los embriones? Crisis de pareja y revocación del consentimiento a la reproducción asistida", en InDret. Revista para el análisis del Derecho. (Barcelona, enero), pp. 1-16.

FARnós Amorós, Esther (2007 b)): "Evans v. The U.K (II): La Gran Sala del

TEDH confirma la imposibilidad de utilizar los preembriones sin el consentimiento de la ex pareja”, en InDret. Revista para el Análisis del Derecho. (Barcelona, abril), pp. 1-6.

FARNós AmOrós, Esther (2011): Consentimiento a la reproducción asistida. Crisis de pareja y disposición de embriones. (Atelier, Barcelona).

Penasa, Simone (2013): “La Corte Europea dei Diritti dell'Uomo di fronte al fattore scientifico: analisi della recente giurisprudenza in materia di procreazione medicalmente assistita e interruzione voluntaria di gravidanza”, en Forum di Quaderni Costituzionali, www.forumcostituzioanli.it, pp. 1-22.

MarTín SÁnCHEZ, María (2008): Matrimonio homosexual y Constitución. (Tirant lo Blanch, Valencia).

SÁnChez MarTíneZ, María Olga (2013): "La reproducción asistida en el contexto de los derechos humanos", en Cad. IberAmer. Direito. Sanit., Brasília (vol. 2, No 2, jul./dez.), pp. 824-838.

Serna Meroño, Encarna (2012): "Las técnicas de reproducción humana asistida: limitaciones para su práctica", en Derecho Privado y Constitución (№ 26, enero-diciembre), pp. 273-307.

Vidal Martínez, Jaime (2011): “Acerca de la Sentencia del Tribunal Europeo de Derechos Humanos. Caso S.H. y otros contra Austria. TEDH 2010/56 de 1 de abril, en materia de reproducción humana asistida y su incidencia en el panorama legislativo europeo", en Revista de Derecho y Genoma Humano, (34), pp. 155-201.

\section{JURISPRUDENCIA CITADA}

Frette contra Francia (2002): Sentencia Tribunal Europeo de Derechos Humanos Estrasburgo (Sección 3a), de 26 de febrero de 2002 (TEDH 2002\156).

Pretty contra Reino Unido (2002): Sentencia Tribunal Europeo de Derechos Humanos Estrasburgo (Sección 4a), de 29 de abril de 2002 (TEDH 2002\23). Vo contra Francia (2004): Sentencia Tribunal Europeo de Derechos Humanos Estrasburgo (Gran Sala), de 8 julio 2004 (TEDH 2004152). 
Hirst contra Reino Unido (2005): Sentencia Tribunal Europeo de Derechos Humanos Estrasburgo, de 6 de febrero de 2005 (TEDH 2005\103).

Dickson contra Reino Unido (2006): Sentencia Tribunal Europeo de Derechos Humanos Estrasburgo (Sección 4a), de 18 de abril de 2006 (TEDH 2006131). Evans contra Reino Unido (2006): Sentencia Tribunal Europeo de Derechos Humanos Estrasburgo (Sección 4a), de 7 marzo 2006 (TEDH 2006\19).

Dickson contra Reino Unido (2007): Sentencia Tribunal Europeo de Derechos Humanos Estrasburgo (Gran Sala), de 4 de diciembre de 2007 (TEDH 2007\86).

Evans contra Reino Unido (2007): Sentencia Tribunal Europeo de Derechos Humanos Estrasburgo (Gran Sala), 10 de abril de 2007.

S.H. y otros contra Austria (2010): Sentencia Tribunal Europeo de Derechos Humanos Estrasburgo (Sección 1a), de 1 de abril de 2010 (TEDH 2010156).

S.H. y otros contra Austria (2011): Sentencia Tribunal Europeo de Derechos Humanos Estrasburgo (Gran Sala), de 3 de noviembre de 2011.

Costa y Pavan contra Italia (2012): Sentencia Tribunal Europeo de Derechos Humanos Estrasburgo (Sala 2), de 28 de agosto de 2012 (TEDH 2012 \72).

Gas y Dubois contra Francia (2012): Sentencia Tribunal Europeo de Derechos Humanos Estrasburgo (sección 5a), de 15 de marzo de 2012 (TEDH 2012\108). 